\title{
A coragem de "ser" no mundo do "ter": contribuições de Paul Tillich para a análise do ser humano na sociedade capitalista atual
}

\author{
Thiago Rafael Englert Kelm*
}

\section{RESUMO}

O presente artigo tem por objetivo analisar as contribuições de Paul Tillich para análise do ser humano na sociedade capitalista atual. Para Tillich, o capitalismo exerce um poder dominante sobre todas as esferas da vida humana, levando as pessoas para dentro de um círculo inescapável e interminável do finito. Nessas circunstâncias o ser humano passa por um processo de coisificação e de perca da dimensão profunda em seu encontro com a realidade. Surge assim o que Tillich chamou de um período marcado pela ansiedade da vacuidade e insignificação. Diante disso, o teólogo propõe a reflexão sobre a coragem de ser no Deus acima do Deus como proposta para repensar o valor da subjetividade individual e o lugar do sentido existencial na vida humana. A coragem de ser, nesse sentido, aponta para a dessacralização do mercado e a relativização de seus pressupostos, uma subjetividade alternativa e portando portadora de um elemento de resistência à lógica do capital.

Palavras-chave: Paul Tillich. Capitalismo. Mercado. Coisificação. Coragem.

\section{THE COURAGE TO "BE" IN THE WORLD OF "HAVING": PAUL TILLICH'S CONTRIBUTIONS ON THE ANALYSIS OF HUMAN BEING IN RECENT CAPITALIST SOCIETY}

\begin{abstract}
This article analyzes Paul Tillich's contributions on the analysis of human being in today's capitalist society. For Tillich, capitalism has a dominant power over all spheres of human life, leading people into an inescap-

* Bacharel em teologia (CEUCLAR). Especialista em Filosofia Contemporânea e História pela Universidade Metodista de São Paulo. Mestrando em Ciências da Religião pela Universidade Metodista de São Paulo; e-mail: thiagoenglert@hotmail.com.
\end{abstract}


able and endless circle of the finite. In such circumstances the human being goes through a process of objectification and miss the profound dimension in their encounter with reality. This raises what Tillich called a period marked by the anxiety of emptiness and meaninglessness. Thus, the theologian proposes a reflection on the courage to be in God above God as proposed to reconsider the value of individual subjectivity and place for meaning in human life. The courage to be, in this sense, points to the desecration of the market and the relativization of its assumptions, an alternative subjectivity and carrying carries a resistance element to the logic of capital.

Keywords: Paul Tillich; capitalism; market; reification; courage

\section{Introdução}

Tillich dedicou boa parte de seus escritos para falar sobre o capitalismo e suas implicações na realidade humana. Embora o teólogo tenha tratado do capitalismo industrial de sua época, é possível encontrar aspectos importantes em seu pensamento que podem lançar luz sobre a condição do ser humano na sociedade capitalista atual. Para Tillich, o capitalismo na medida em que se coloca como norma absoluta na sociedade, acaba por dirigir o espírito humano para dentro do círculo inescapável e interminável do finito, e isso consequentemente desemboca em modos aviltantes da dignidade humana.

Nessas circunstâncias o ser humano passa por um processo de coisificação e de perca da dimensão profunda em seu encontro com a realidade. Para Tillich, essa perca de profundidade caracteriza a situação atual do ser humano marcado pela vacuidade e insignificação existencial. Esta situação é o que teólogo chama de terceiro período de ansiedade da vacuidade e insignificação. Diante disso o teólogo propõe uma reflexão sobre coragem de ser no Deus acima de Deus como superação desse estado existencial. Sendo assim, a presente pesquisa tem por objetivo analisar de que maneira o teólogo aborda a questão da situação do ser humano na sociedade capitalista e de que maneira essa abordagem tillichiana pode ser articulada com a realidade do ser humano atual.

\section{O caráter totalitário do capitalismo na sociedade atual}

De acordo com Tillich (2009) a cultura atual é marcada pelo movimento predominante da sociedade industrial. Este é um espírito que 
vai além da sociedade burguesa em que é mais concretamente visível, e se percebe especialmente nos três produtos mais representativos do século XIX: a ciência natural matemática, a tecnologia e a economia capitalista. O teólogo entende que a modernidade no sentido mais amplo da palavra é capitalista, e que este sistema, com todas as suas consequências, é o que determina a situação religiosa e cultural mais do que qualquer outra coisa (TILLICH, 1936)

Embora o teólogo tenha tratado sobre o capitalismo industrial de sua época, a discussão sobre a predominância da economia de livre mercado presente em seu pensamento ainda encontra lugar nas discussões contemporâneas. Em articulação com a proposta de Tillich, pode-se pensar o capitalismo atual como uma "confluência de vocação imperial e, por isso, uma particular 'encarnação' do errante espírito do Império" (MÍGUEZ; RIEGER; SUNG, 2012, p. 11) Para os autores, este Império global possui a pretensão de levar todo o mundo a se conformar com um único modo de operar no econômico, de conceber o político, de gerir poder e de estar sob uma suprema força militar.

Tal predominância imperial pode ser observada na reivindicação que o restrito setor da classe global faz de firmar-se como dono do mundo. Tudo se torna precário diante do poder do Império que coloca as leis do mercado no centro de seu sistema valorativo (MÍGUEZ; RIEGER; SUNG, 2012). De acordo com Yip (2010) esse sistema não implica apenas na hegemonia da lógica do capital sobre o âmbito econômico e político mas também sobre outras esferas sociais, como moralidade, religião e na própria conduta de vida e constituição de identidade das pessoas. De acordo com Tillich, as pessoas "conscientemente ou não tornaram-se parte de um processo objetivo que lhes determina a vida em todas as dimensões, desde a econômica até a espiritual" (TILLICH, 1992, p. 276)

O capitalismo, portanto, não se reduz apenas a um modo de produção, mas é também uma ordem social em que o mercado ocupa o lugar de dominação. As significações, sentido da vida e até mesmo os direitos humanos são invertidos e tergiversados. O capitalismo adquire um caráter totalitário e acaba formando não apenas estruturas políticas e econômicas como também realidades culturais, intelectuais e pessoais, por consequência, tudo mais fica submetido à lei do lucro (MÍGUEZ; 
RIEGER; SUNG, 2012). Dessa forma, a lógica do capital pode adquirir, em muitos aspectos, um caráter de ultimidade existencial, e nesse sentido Tillich afirma que:

Este é o "deus" de muitas pessoas no mundo ocidental, dominado pelo espírito de concorrência. Como todo interesse último, também ele reivindica obediência incondicional às suas leis, mesmo que isso signifique que a pessoa terá que sacrificar relações humanas genuínas, convicções próprias e criatividade. Sua ameaça é decadência social e econômica; sua promessa - vaga como todas as promessas desse tipo - , a realização da própria essência (TILLICH, 1985, p. 7)

É em torno deste aspecto dominador do capitalismo que as pesquisas de Tillich se concentram. O teólogo não deixa de analisar o impacto do capitalismo sobre a política e economia, porém sua concentração está mais voltada para a dimensão cultural-espiritual. Nesse sentido, o teólogo afirma que o ser humano da "sociedade industrial" vive cercado por muitas ameaças como a miséria, injustiça, sujeição aos métodos de consumo e a posição da pessoa como "objeto" de produção, mas destaca que "O pior elemento presente em tal situação não é a miséria econômica resultante do desemprego, mas o sentimento da absoluta falta de sentido" (TILLICH, 1992, p. 256). A abordagem de Tillich tenta perceber portanto este modo de ser-no-mundo de um ser humano "coisificado" e sujeito aos métodos de consumo.

De acordo com Tillich (2009) uma das primeiras características da sociedade industrial "é a concentração das atividades humanas na pesquisa metódica e na transformação técnica do mundo e das pessoas, com a consequente perda da dimensão da profundidade no encontro com a realidade" (TILLICH, 2009, p. 84). Tillich entende que na lógica de mercado, a realidade passa a ser compreendida em termos puramente técnicos e isso consequentemente acaba anulando a transparência do ser humano para o eterno. $\mathrm{Na}$ estrutura do capitalismo, todas as coisas são transformadas em produtos e por consequência, esvaziadas de seu sentido mais profundo. Pouco importa a "áurea" das coisas, mas sua disponibilização ao consumo.

Para Tillich (2009) neste sistema marcado pela falta de profundidade, o universo torna-se autossuficiente, e passa a ser calculável, 
controlável e passível de ser modificado de acordo às necessidades e desejos humanos. Dessa forma, o ser humano foi volvendo-se mestre do universo e Deus tornou-se supérfluo e por isso foi colocado de lado, para não interferir nos cálculos comerciais. Nesse sentido, as conquistas científicas e técnicas são vistas como o caminho para o progresso e união/salvação da humanidade. E nesta caminhada, o ser humano é quem desempenha o papel fundamental.

O teólogo afirma que nessa perspectiva o ser humano é visto como estando em seu estado essencial, "É representado como realização progressiva de nossas potencialidades [...] Assim, apesar de nossas falhas, não há mais pecados nem pessoal nem universal. A escravidão da vontade, mencionada pelo Reformador, é negada" e "O ajuste da grande maioria dos seres humanos ao sistema de produção e consumo, faz-se por meio de processos educacionais" (TILLICH, 2009, p. 85). Nega-se as ambiguidades intrínseca do sistema. De acordo com Sung (2010) este mito do progresso e a construção de um novo tipo de utopia é o que caracteriza a modernidade e sua crença de que a tecnologia tornaria possível o acúmulo ilimitado de riqueza e por consequência a satisfação de um conjunto cada vez maior de desejos humanos. O progresso tecnológico seria, portanto, a chave para a satisfação de todos estes desejos e de onde se esperaria a salvação.

Entretanto esta promessa é sem garantias, pois o modelo de desejo está sempre inovando no seu consumo, e mesmo as pessoas com alto poder aquisitivo, estão fadadas à constante insatisfação. Ou seja, a insatisfação será sempre uma realidade presente na dinâmica dos desejos humanos e a busca por satisfaze-los plenamente é o que move as pessoas para dentro de um modo de vida não refletida, sem profundidade e coisificante. Tillich aponta para o caráter ambíguo das promessas capitalistas e afirma que constantemente "se nega seu caráter inescapavelmente trágico" (TILLICH, 2009, p. 86) Nesse sentido o teólogo afirma que:

Achamos que somos mestres do mundo e de nós mesmos. Mas, na verdade, fazemos parte da realidade que criamos, objetos entre objetos, coisas entre coisas, parte da engrenagem da máquina universal, à qual devemos nos adaptar para que ela não nos esmague. Essa adaptação nos transforma em meios para fins que também, por sua vez, são meios, sem finalidade alguma. (TILLICH, 2009, p. 87) 
As promessas capitalistas são, portanto, sem garantias e trágicas. O progresso humano por meio do consumo e satisfação dos desejos apontam necessariamente para um fim trágico. O espírito do Império, na medida em que passa a exercer seu domínio em todas as esferas da vida humana, forma um "modo de ser imperial" (MÍGUEZ; RIEGER; SUNG, 2012, p. 11) que deposita no consumismo e avanço tecnológico a esperança do progresso e realização humana. É uma forma de ser no mundo que busca na satisfação imediata de seus desejos as possibilidades de realização do ser, isto é, buscam no "ter" as possibilidades de "ser".

De acordo com Sung (2010) o desejo é algo constitutivo do ser humano, porém, no capitalismo este desejo de ter não apenas se tornou central como está assumindo proporções de totalidade. Em outras palavras, a possibilidade de "ser", e de encontrar sentido existencial é buscado no "ter" que se dá sempre a partir da lógica de consumo. Nizan Guanaes, empresário e publicitário brasileiro, num texto em que fala sobre a Nike, escreveu que:

Nike é um estilo e uma visão de mundo. Seus anúncios são evangélicos. Não vendem apenas, doutrinam. Não convencem só, convertem [...] Nike faz o menino do subúrbio americano, o garotão do meio-oeste ou um waspzinho de Sutton Place se sentir um jogador de basquete vindo do Harlem. E, that's cool, man. Nike faz a mulher separada e celulitária se sentir Fernanda Keller só porque deu três voltas no quarteirão. De Nike, é claro. Nike faz o boy do Terceiro Mundo se sentir tão bem quanto se se tivesse cheirado cola. Por isso um monte de boy que não podia ter Nike tem Nike. Porque se não tiver ele morre. Boy é cabeça, tronco e Nike. (GUANAES, 1994)

Conforme Sung (2010) "Nike", assim como outras marcas que estejam na moda e que são objeto de desejo de todos, passou a ser uma condição para pertencer à comunidade humana. "As pessoas não compram um tênis, mas sim vão em busca do 'ser' gente que lhes possibilita ser reconhecida nas relações com outras pessoas da comunidade que vivem sob este tabu" (SUNG, 2010, p.73) Dessa forma, a formação do si próprio se desenvolve nessa lógica, ou seja, o reconhecimento de si como pessoa se da na medida em que se consegue satisfazer, parcialmente, o desejo de ter. Nesse sentido, "Os consumidores modernos podem identificar-se pela fórmula: eu sou $=$ o que tenho e o que con- 
sumo" (FROMM, 1987, p. 45) O ter se torna critério para ser, e nessa dinâmica, o ser humano é coisificado e tornado parte da engrenagem da máquina universal, coisas entre coisas, objetos entre objetos.

$\mathrm{O}$ "ter" gera necessariamente uma orientação para com o "eu" e o "outro" que é pautada sobre as leis do mercado. O "ter", portanto passa a ocupar a totalidade do pensar, sentir e agir das pessoas. Os desdobramentos destrutivos desta maneira de ser-no-mundo aparece na medida em que o outro é sacrificado para que as leis do mercado (adquirir, possuir e obter lucro) possam ser cumpridas. Nesse tipo de dinâmica, o outro é transformado em coisa e o relacionamento com ele passa a ser de pertença e posse. Tudo e todos, inclusive o próprio eu, se tornam propriedades particulares. Atitude em relação as coisas se torna ausente de amor, o senso de comunidade é inexistente e o que prevalece na verdade é o senso de dominação. Nas palavras de Tillich:

Esta atitude sem amor e dominadora em relação às coisas, possui um efeito duplo. Ela emancipa os homens das coisas santas finitas que reivindicam para si próprias a santidade do eterno; ele os libera de uma escravidão santificada para coisas e exalta a personalidade sobre o reino completo das coisas. Este é o efeito protestante da economia liberal. Ao mesmo tempo, no entanto, limita a personalidade pressionando-a para um serviço sem fim na regra sobre coisas empobrecidas. Assim a própria personalidade é empobrecida e devota ao mundo do finito. Este é o efeito do espírito capitalista na economia liberal (TILLICH, 1956)

De acordo com Tillich (1956) esta é uma das características mais pesadas do tempo capitalista. O aguilhão do desejo ilimitado não permite que o espírito se volte para qualquer coisa que não serve o próprio tempo. Outras dimensões da vida comum são colocadas como secundária e a dimensão profunda do ser humano é negada. O capitalismo leva o espírito humano para dentro do círculo inescapável e interminável do finito e a humanidade perde seu valor intrinsicamente humano.

A forma técnica da produção monopolista não só de bens materiais como de bens espirituais, transformou o indivíduo, tanto na produção como no consumo em mera parte de uma máquina toda abrangedora, movida por forças anônimas. [...] Não só criou máquinas, todas iguais, mas também, seres humanos "em série", condicionados pelo rádio, pelo cinema, pelos 
jornais e pelo ajustamento educacional, capaz de produzir o conformismo sub-humano em face desse imenso processo (TILLICH, 1992, p. 277)

O empobrecimento da personalidade e a devoção ao mundo finito demonstra o caráter destrutivo do mercado idolatrizado que prende as pessoas numa realidade coisificante e sem profundidade. Este modo de ter não se estabelece por um processo vivo e criativo entre o sujeito e o objeto, pois ambos envolvidos na dinâmica são coisificados, e por isso a relação é de inércia e não de vida, ou como afirma Tillich, estabelece-se uma dinâmica de "vitalidade reduzida" (TILLICH, 1976, p. 61)

É dessa forma que a presença dominante do capitalismo sobre a cultura e a vida humana em suas muitas esferas tem se estabelecido. Daí decorre a desumanização como um desdobramento desse modo "ter" de existir e a exigência de devoção e obediência incondicional feita pelo capitalismo. Para Tillich, neste cenário de coisificação humana a coragem de ser é enfraquecida e a vida individual e social fica marcada por uma profunda desintegração existencial que se desdobra em atitudes destrutivas da existência humana. Estas atitudes estariam marcando profundamente a condição do ser humano pós-moderno caracterizado sobretudo por um vazio existencial e falta de sentido.

\section{A experiência ansiosa da vacuidade e insignificação como consequência da supervalorização do "ter".}

De acordo com Tillich (1976) o progresso do liberalismo econômico bem como a ascensão de uma civilização técnica com sua própria desintegração incipiente são os pressupostos para um período dominante de ansiedade da vacuidade e insignificação. Uma maneira de ser-no-mundo que incorpora a dinâmica e os valores da sociedade capitalista, mas que longe de levar a humanidade para um progresso real, irrompe em modos aviltantes da dignidade humana. Em outras palavras, Tillich descreve que este modo imperial de ser é um modelo fadado à vacuidade e insignificação existencial.

Situações sociais como as descritas têm ao mesmo tempo o caráter de uma armadilha sem saída e de um vácuo vazio, negro e desconhecido. Ambas as faces da mesma realidade despertam a ansiedade latente de 
cada indivíduo que as contempla. Hoje, a maior parte de nós está a olhá-las (TILLICH, 1976, p. 48).

Tal situação pode ser observada na sociedade capitalista pós-moderna e sua multidão de pessoas ansiosas, individualistas e egoístas. Este ser humano pós-moderno como afirma Santos (2004, p. 23) “é o indivíduo mecanizado, solitário na multidão das grandes cidades, desumanizado". O progresso do Império do capital aproxima as pessoas mas cria uma grande distância entre elas. Essa aproximação se dá através de relações plásticas e frágeis, muitas vezes motivadas por algum tipo de interesse em benefício próprio. A lógica competitiva e o interesse em si mesmo geram um distanciamento cada vez maior entre as pessoas. Esta forma de ser no mundo expressa o que Fromm chamou de aspectos negativos do caráter humano, "pessoas com falta de imaginação, mesquinhez, desconfiança, frieza, ansiedade, obstinação, indolência, pedantismo, obsessão e desejo de posse" (FROMM, 1984, p. 90-91).

De acordo com Tillich (2009) a genuína comunidade entre os seres humanos é possível apenas nesse mundo, mas se esse mundo se tornar intolerável, os indivíduos se voltarão para a experiência da solidão, obrigados a tecer sonhos que mais ainda os isolarão.

Tillich (2011) afirma que as estruturas destrutivas do ser humano como mecanização e objetivação, solidão e submissão, angustia, medo, etc. são universalmente humanas, ou seja, se referem a própria condição humana enquanto situação da alienação existencial. Entretanto, estas situações não são as únicas marcas da existência, e por isso devem ser contrabalançadas pelas estruturas de cura e reunião daquilo que está alienado. Contudo, as estruturas sociais podem tirar das pessoas a possibilidade de enfrentar o não-ser, e quando isto acontece, a ansiedade explode em todos os lados. Esta ausência das possibilidades de cura ou superação é parte estruturante da dinâmica das sociedades capitalistas.

Walter Benjamim (2013), percebe que no "culto" produzido pelo capitalismo, não existe conteúdo expiatório, mas apenas culpabilizador, o culto é realizado não para expiar a culpa "mas para torna-la universal, para martela-la na consciência e, por fim e acima de tudo, envolver o próprio Deus nessa culpa, para que ele se interesse pela expiação" (BENJAMIN, 2013, p. 22). O capitalismo dessa forma deixa de ser 
reforma do ser, antes é seu esfacelamento, eleva o desespero ao estado religioso universal. Isso faz da cura e reunião algo inviável, e o que se tem portanto é um estado de desespero e ansiedade causado por um modo de ser no mundo que é destrutivo.

Nesse sentido, a sociedade capitalista em que vive o ser humano pós-moderno não apenas deu origem a pessoas egoístas, competitivas, mesquinhas, etc. Mas também pessoas profundamente marcadas por um esvaziamento de sentido e assombradas por medos, ansiedade, vazio, insignificação, e outros estados de espírito oriundos da dimensão abismal do não-ser. Tillich entende que "o progresso do liberalismo e democracia, a ascensão de uma civilização técnica com sua vitória sobre todos os inimigos, e sua própria desintegração incipiente - estes são pressupostos sociológicos para o terceiro período principal da ansiedade. Neste, a ansiedade da vacuidade e insignificação é dominante. Estamos sob a ameaça do não ser espiritual" (TILLICH, 1976, p. 47)

A vida nestas circunstancia leva o ser humano consequentemente à uma frustração existencial. De acordo com Tillich (1956) essa devoção ao mercado vai resultar sempre num empobrecimento da personalidade e a destruição da pessoa como tal. Ao falar sobre o capitalismo como religião Benjamim afirma que nesse sentido "a religião não é mais reforma do ser, mas seu esfacelamento. Ela é a expansão do desespero ao estado religioso universal, do qual se esperaria a salvação" (BENJAMIN, 2013, p. 22). Adaptar-se plenamente às exigências do sistema capitalista é o único método de salvação apresentado pelo sistema. Aqui a pessoa é consequentemente levada a uma crise de sentido que, para Sennett (2009), desencadeia a corrosão do caráter que se manifesta na perca da identidade. Para Tillich, nesta adulteração o ser humano é levado fatalmente à frustração existencial que solapa as bases da existência. "Resultam daí experiências de vazio e falta de sentido, de desumanização e alienação. Não mais achamos sentido na realidade que, em suas formas e estruturas, nada nos diz" (TILLICH, 2009, p. 87).

Entretanto, este estado existencial de vacuidade e insignificação jaz encoberto pela fumaça de uma sociedade espetacularizada, como muito bem observou Guy Debord. De acordo com Debord (1997) o modo de produção capitalista deu origem a uma sociedade de espetáculo que se apresenta como modelo dominante na vida social. $\mathrm{Na}$ espetacularização 
da vida, a sociedade cria uma imagem de si mesma sob as bases das representações, de modo que aquilo que é real se perde na ilusão representada em forma de espetáculo. Para o autor, essa realidade reflete em sua própria unidade geral um falso mundo à parte, essa especialização das imagens do mundo acaba numa imagem autonomizada, onde o mentiroso mente a si próprio.

Nesse sentido, o espetáculo não é somente um conjunto de imagens, mas uma relação social entre as pessoas mediada por imagens. Debord ao explicar o que é o espetáculo, aponta para a dinâmica das relações pessoais e identifica relações baseadas em aparências sem qualquer autenticidade. Nestes moldes, o público se torna por completo um consumidor daquilo que lhe é oferecido, assumindo desta forma, uma postura passiva e de não crítica à realidade que se apresenta. Nesse cenário, a capacidade humana de refletir sobre a situação é influenciada e fica refém do espetáculo.

Para Tillich, o ser humano do século XX (e aqui pode-se incluir o ser humano atual) perdeu um mundo significante e um eu, que vive em significações fora de um centro espiritual. Este mundo de objetos criado pelo ser humano arrastou para dentro de si aquele que o criou, e que agora perde sua subjetividade nele. "Ele sacrificou-se às suas próprias produções" (TILLICH, 1976, p. 109). As coisas secundárias tornaram-se as prioridades das paixões humanas e com isso uma realidade quase insuportável se apresenta como o melhor dos mundos possíveis.

A hipocrisia paira sobre as relações sociais que se constroem artificialmente nas muitas formas de grupos humanos (escolas, casas, religiões, etc.) As conversas são permeadas por elogios e pautadas sobre uma busca masturbatória de exaltação do próprio ego, poucas coisas ditas são de fato oriunda do amago da alma humana e quase não se houve palavras que possam incitar a vida nas dimensões profundas e vazias das pessoas. A superficialidade reina. O espetáculo esconde os verdadeiros seres coisificados, solitários, egoístas, desesperados, repletos de medo, fúria e frustração. A vida se transforma na busca pela satisfação dos desejos que prometem "salvação" quando satisfeitos. "Nesse contexto, surge o neo-individualismo pós-moderno, no qual o sujeito vive sem projetos, sem ideais, a não ser cultuar sua auto-imagem e buscar a sa- 
tisfação aqui e agora. Narcisista e vazio, desenvolto e apático, ele está no centro da crise de valores pós-moderna" (SANTOS, 2004, p. 30)

De acordo com Marques (2010) surge daí um mundo doente e consequentemente pessoas doentes. O ser humano é levado a adorar o mundo das coisas, esse sentimento determinado pelos valores do mercado vai adquirindo proporções gigantescas e se tornando dominante na sociedade, configurando com isso o ser humano capitalista pós-moderno. Um modo de ser no mundo em que:

o medo, problemas psíquicos, enfim, um mal estar constante será uma característica fundamental e constante em sua vida. Isso provoca a dominação da morte sobre a vida, como pode ser visto no crescente índice de suicídio e na generalização das guerras, da exploração e opressão social (MARQUES, 2010, p. 28)

A espetacularização da vida do ser humano pós-moderno caminha em direção a este mal estar existencial que pode levar, em muitos casos, à dominação da morte sobre a vida. De acordo com Santos (2004) dando adeus às ilusões, o ser humano pós-moderno consciente de que não há céu nem sentido para a história, se entrega ao presente e ao prazer, ao consumo e ao individualismo. Ele encarna um estilo de vida em que prevalece o niilismo, o nada, o vazio, a ausência de valores e de sentido para a vida.

Esta realidade para Tillich (1976) representa a ameaça de uma perda infinita, a saber, a perda do "eu" pessoal de cada indivíduo. O eu individual se torna um espaço vazio e o mensageiro de algo que não é ele próprio. Algo estranho mediante o qual o eu é extraviado de si próprio.

A segurança, que é garantida pelos mecanismos bem funcionantes para controle da pessoa, pelo controle organizacional da sociedade rapidamente incrementado - esta segurança é comprada por um alto preço: o homem para quem tudo isso foi inventado como meio, tornou-se um meio ele próprio, a serviço dos meios" (TILLICH, 1976, p. 108)

Para Tillich (1976) o ser humano do século XX perdeu um mundo significante e um eu, que vive em significações fora de um centro espiritual. Essa perca de personalidade e senso comunitário expressa a desintegração espiritual em que vivem as pessoas. "Quando se perde 
a personalidade e a comunidade é porque já se perdeu, antes, o sentido profundo da vida" (TILLICH, 1992, p. 278) O mundo de coisas criado pelo ser humano puxou para dentro de si aquele que o criou, e que agora perde sua subjetividade nele. Os processos econômicos e técnicos preparavam o monstruoso mecanismo que acabou por devorar as pessoas e a dinâmica saudável de suas relações.

\section{A coragem de ser como superação do modo "ter"}

A presença dominante do espírito capitalista que marca a realidade atual, de acordo com Tillich (1976), resultou numa condição existencial marcada pela ansiedade da dúvida e insignificação. Em outras palavras, é a perca do sentido profundo da vida. "Se contudo, a dúvida e a insignificação prevalecem, experimenta-se um abismo no qual a significação da vida e a verdade da responsabilidade fundamental desaparecem [...] A questão então é: Há uma coragem que possa vencer a ansiedade da dúvida e insignificação" (TILLICH, 1976, p. 135). A proposta de acordo com o teólogo deve iniciar com a aceitação do estado de insignificação, ou seja, é preciso assumir a situação. A resposta para este estado não é resposta se ela requer a remoção desse estado, pois "Aquele que está nas garras da dúvida e insignificação não pode se libertar destas garras; mas ele pede uma resposta que seja válida dentro, e não fora, da situação de desespero" (TILLICH, 1976, p. 136)

A resposta só é possível na medida em que não se tenta escapar dessa questão. De acordo com Fromm (1987) as possibilidades de mudança só podem ser bem sucedidas na medida em que as pessoas forem intransigentes realistas, não se apegando a ilusões e considerando plenamente as dificuldades. Tillich (1976, p. 136) afirma que "nos aceitamos como aceitos, a despeito de nosso desespero sobre a significação dessa aceitação. [...] A fé que tornar a coragem do desespero possível é a aceitação da potência de ser, mesmo nas garras do não-ser". O ser humano coisificado ainda é ser humano, e exatamente a partir de seu estado de coisificação e insignificação que a potência do ser orienta o ser humano para o real sentido do ser que vence o não-ser presente na coisificação. O ser humano se afirma como tal e reivindica a preservação de sua dignidade enquanto humano. 
Aceitar a insignificação é um ato de fé, de coragem existencial. Mas a fé que possibilita a coragem para incorporá-las, em si não possui conteúdo especial. "É simplesmente fé, não dirigida, absoluta. É indefinível, uma vez que tudo que é definido é dissolvido pela dúvida e significação" (TILLICH, 1976, p. 137). A fé nesse sentido possibilita o ser realizar-se contra a resistência de outros seres. É um olhar voltado para as dimensões subjetivas e profunda da realidade, que percebe na realidade a sua inesgotabilidade, consciente das condições constitutivas da subjetividade individual.

A auto-afirmação divina é o poder que torna possível a auto-afirmação do ser finito, a coragem de ser. Só porque o ser-em-si tem o caráter de auto-afirmação a despeito do não-ser é possível coragem. A coragem participa da auto-afirmação do ser-em-si, participa da potência de ser que prevalece contra o não-ser. Aquele que recebe esta potência em um ato de fé, mística ou pessoal ou absoluta, tem consciência da fonte de sua coragem de ser (TILLICH, 1976, p. 140)

Nesse ato da coragem de ser a potência de ser é efetiva na pessoa, quer ela reconheça ou não, e cada ato dessa coragem é uma manifestação do fundamento do ser. Trazer à consciência a experiência do fundamento do ser é uma atitude necessária para superar o estado de coisificação decorrente do espírito do Império. O fundamento do ser permite a vivência do poder de ser que supera o não-ser e nesse sentido eleva a vida humana num sentido auto-transcendente para além da realidade puramente técnica e objetiva. Se para Tillich a principal característica do sistema capitalista é a concentração das atividades humanas na transformação técnica do mundo e das pessoas, e por consequência, a perca da dimensão de profundidade no encontro com a realidade, então a experiência da fé como coragem de ser é a retomada da consciência nas dimensões profundas e espirituais da realidade. Isto é, um direcionamento intencional ao incondicionado. A realidade que se percebe é a dimensão de profundidade presente na vida humana, uma realidade não objetivável e incondicional. É realidade divina que se manifesta como sendo estrutura do ser ao mesmo tempo em que a transcende infinitamente. 
A consciência da auto-transcendência leva o ser humano a se perguntar pela vida não-ambígua, por algo que possa superar as ambiguidades da vida e possibilitar a cura existencial. Deus além de Deus é a resposta para a vida não ambígua. De acordo com Tillich (1976, p. 143) "A fonte básica da coragem de ser é o 'Deus acima de Deus' [...] Somente transcendendo o Deus do teísmo pode a ansiedade da dúvida e insignificação ser incorporada à coragem de ser". Na medida em que a coragem de ser incorpora a noção de Deus além de Deus, nada mais que esteja presente na realidade finita poderá ser objeto de preocupação última. Dessa forma, o Deus acima do Deus do teísmo evita a perda de si próprio, torna o ser humano uma parte daquilo que não é também uma parte, mas a base do todo. $\mathrm{O}$ eu não se perde num todo maior que o submerge na vida de um grupo limitado. A noção de Deus acima do Deus não absorve o ser como faz qualquer todo limitado, todo coletivismo e todo conformismo. Por isso, a igreja que representa a potência do Deus que transcende o Deus das religiões reivindica ser a mediadora da coragem de ser.

Mas uma igreja que levanta a si mesma, em sua mensagem e sua devoção, ao Deus acima de Deus do teísmo, sem sacrificar seus símbolos concretos, pode ser intermediária de uma coragem que incorpora em si a dúvida e a insignificação. É a Igreja sob a Cruz que sozinha pode fazer isto, a Igreja que prega o Crucificado, que gritou para o Deus que permanecia seu Deus depois que o Deus da confiança o havia abandonado nas trevas da dúvida e insignificação. Ser como uma parte em tal igreja é receber uma coragem de ser na qual podemos perder nosso eu e na qual recebemos nosso mundo (TILLICH, 1976, p. 145)

Nem o Deus do teísmo e nem mesmo o mercado idolatrizado poderá ocupar esse lugar. O ser humano encontra sentido naquilo que está além dos símbolos, embora isso aconteça através dos símbolos, mas não mais nos símbolos absolutizados. O estado de ser tomado pelo Deus acima do Deus não é um estado que aparece ao lado de outros estados na mente. Nunca se trata de algo definido ou separado, um evento que possa ser descrito ou isolado. Se trata da situação dentro do limite das possibilidades do ser humano. É o limite. "Não é um lugar onde se possa viver, é sem a segurança de palavras e conceitos, é sem nome, sem igreja, sem culto, sem teologia. Mas está se movendo nas 
profundezas de todo eles. É a potência de ser, da qual eles participam e da qual são expressões fragmentárias" (TILLICH, 1976, p. 146) Da mesma forma, quando os símbolos tradicionais perderem seu poder, aquilo que uma vez foi a potência nestes símbolos, ainda estará presente e dará origem a coragem de ser a despeito da experiência de um mundo caótico e de uma existência finita. "Retorna com a fé absoluta que diz Sim ao ser, sem ver nada concreto que possa vencer o não-ser no destino e na morte" (TILLICH, 1976, p. 146)

O sentido de ser não se restringe ao que é puramente finito, mas ele percebe na finitude a auto-transcendência, de que as coisas não se limitam a razão técnica. De acordo com Fromm (1987, p. 192) "a orientação no sentido de ser é um forte potencial humano" e na medida em que o ser humano se percebe auto-transcendente e experimenta a coragem de ser no Deus acima de Deus é possível pensar numa relativização do "ter" como modo de ser. Ou seja, o ser deixa de ser buscado somente no "ter". O consumismo como meio de cura perde seu poder salvífico se a realidade humana for entendida como possuindo uma dimensão de profundidade auto-transcendente. A orientação humana na busca pelo sentido já não mais se limita à satisfação de desejos, pois percebe nesse ato a presença ambígua da existência e portanto sua incapacidade de cura existencial. A cura dada na fé, é sobretudo, a libertação de todas as cadeias da lógica do capital.

O Deus acima do Deus na medida em que evita que símbolos concretos sejam absolutizados possibilita também as bases para se pensar numa resistência contra o Império do capital. O Império deixa de ser o sagrado, suas promessas de cura (progresso) se tornam ambíguas como tudo mais e portanto incapazes de responder à pergunta humana pela superação das ambiguidades. Seus símbolos sagrados são relativizados e não mais visto como norma absoluta para o ser. A coragem de ser é percebida então para além da lógica imperial, no Deus acima do deus mercado.

A experiência da coragem de ser no Deus acima de Deus é a experiência que se da nas dimensões profunda do ser. É, portanto, esta experiência da coragem de ser, que em princípio é indefinível e que resgata o valor da subjetividade enquanto direcionamento da consciência para a substância das formas e não somente para as formas. É 
a experiência do incondicional na realidade finita que se mostra e se esconde como o poder de ser de tudo o que é e que vence o não-ser. É o ser que não se define mas que se comunica mediante a comunhão na experiência do ser. É a experiência do Deus que se mostra mais próximo da pessoa do que a pessoa dela mesma, é o Deus presente nas estruturas do ser e que ajuda a recuperar os fundamentos da sociedade humana. É o Deus que afirma o ser e restabelece a coragem de existir numa sociedade marcada pela desumanização capitalista.

\section{Considerações finais}

Mesmo após cinquenta anos de sua morte, Tillich continua contribuindo com a empreitada de denunciar o caráter destrutivo do sistema capitalista. É possível perceber que mesmo escrito numa época diferente, o pensamento de Tillich ecoa na realidade da vida pós-moderna. Para o teólogo, a predominância do capitalismo sobre todas as esferas da vida com a consequente coisificação do ser humano resultaria necessariamente na perca da dimensão profunda do ser e em num estado de vacuidade e insignificação. Como afirmou Santos (2004) este é o estado do ser humano pós-moderno. Um modo de ser no mundo que busca sentido na satisfação dos desejos por meio do consumo. É o indivíduo mecanizado, solitário na multidão das grandes cidades, desumanizado e egoísta. Essa absolutização do mercado, de acordo com Tillich, leva fatalmente à frustração existencial e na possível dominação da morte sobre a vida.

$\mathrm{Na}$ tentativa de chamar atenção para o resgate do valor do ser, Tillich propôs a coragem de ser no Deus acima do Deus. Nessa experiência arraigada nas profundezas do ser, o "ter" deixa de ser a norma absoluta das relações humanas e o consumismo enquanto meio de salvação é enfraquecido. Sendo assim, é possível dizer que a coragem de ser fundamentada no Deus acima do Deus aponta para a dessacralização do mercado e a relativização de todos seus pressupostos. Essa proposta tillichiana pode ser entendida como uma subjetividade alternativa e portando portadora de um fator de resistência não totalmente controlável pelo Status quo. É a profanação do "sagrado" capital e de sua lógica utilitarista, e quando se profana o "ter", a atenção se volta para o "ser". 


\section{Referências}

BENJAMIN, Walter. O capitalismo como religião. São Paulo: Boitempo, 2013. FROMM, Erich. Psicanálise da Sociedade Contemporânea. São Paulo, Círculo do Livro, 1984.

Ter ou Ser? 4 ed.. Rio de Janeiro: LTC, 1987

GUANAES, Nizan. "Nike é um estilo e uma visão do mundo", Folha de São Paulo, 1994. Disponível em: < http://www1.folha.uol.com.br/fsp/1994/5/02/ dinheiro/14.html >. Acesso em: 02 jun. 2016.

DEBORD, Guy. A sociedade do Espetáculo. Rio de Janeiro: Contraponto, 1997.

MARQUES, Edmilson Ferreira. O ser humano da sociedade capitalista na concepção de Erich Fromm. Revista Espaço Acadêmico, V. 10. N. 110, jul. 2010. Disponível em: $<$ http://www.periodicos.uem.br/ojs/index.php/EspacoAcademico/article/viewFile/10498/5774>. Acesso em: 04 jun. 2015.

MÍGUEZ, Néstor; RIEGER, Joerg; SUNG, Jung Mo. Para além do espírito do Império: novas perspectivas em política e religião. São Paulo: Paulinas, 2012.

SANTOS, Jair Ferreira dos. O que é Pós-moderno. São Paulo: Brasiliense, 2004.

SENNETT, Richard. A corrosão do Caráter. São Paulo: Record, 2009.

SUNG, Jung Mo. Desejo Mercado e Religião. São Paulo: 4. ed. Revista e ampliada. Fonte Editorial, 2010.

TILLICH, Paul. A coragem de ser. Rio de Janeiro: Paz e Terra, 1976.

. A era protestante. São Bernardo- SP: Ciências da Religião, 1992

. Dinâmica da fé. 3. ed. São Leopoldo, RS: Sinodal, 1985.

. Teologia da Cultura. São Paulo: Fonte Editorial, 2009.

. Teologia sistemática. 6. ed. São Leopoldo: Sinodal, 2011.

. The Interpretation of History. 1936. Disponível em: <http://www. religion-online.org/showbook.asp?title=377>. Acesso em: 01 jun. 2016.

. The religious situation. 1956. Disponível em: $<$ http://www.religion-online.org/showbook.asp?title=376>. Acesso em: 01 jun. 2016.

YIP, Francis Ching-Wah; Capitalism as religion? A study of Paul Tillich's interpretation of modernity. Massachusetts: Harvard, 2010. 